\title{
Percutaneous mitral valvuloplasty in the modern era
}

Saccocci, Matteo ; Taramasso, Maurizio ; Maisano, Francesco

DOI: https://doi.org/10.5603/KP.2018.0095

Posted at the Zurich Open Repository and Archive, University of Zurich ZORA URL: https://doi.org/10.5167/uzh-164925

Journal Article

Published Version

Originally published at:

Saccocci, Matteo; Taramasso, Maurizio; Maisano, Francesco (2018). Percutaneous mitral valvuloplasty in the modern era. Kardiologia Polska, 76(5):819-820.

DOI: https://doi.org/10.5603/KP.2018.0095 


\title{
Percutaneous mitral valvuloplasty in the modern era
}

\author{
Matteo Saccocci, Maurizio Taramasso, Francesco Maisano \\ Heart Valve Centre, University Hospital of Zürich, CH - Department of Cardiovascular Surgery, Zürich, Switzerland
}

Article Tyczyński et al., see p. 845

Most of the innovative technologies used in percutaneous mitral interventions are based on well-standardised surgical procedures such as edge-to-edge repair or mitral annuloplasty.

One of the first successful attempts to replicate surgical procedures in percutaneous interventions was represented by percutaneous balloon mitral valve commissurotomy (PMC). It dates back to 1984 when Inoue et al. [1] published the results of the first patients treated with transseptal mitral valvuloplasty for severe mitral stenosis (MS) in Japan. The Inoue balloon inserted from the femoral vein, usually sized according to the patient's height, allowed a controlled dilatation of the valve to split the fused commissures and to obtain a significant increase of the mitral valve area (MVA).

Having started as an experimental treatment for inoperable patients, PMC rapidly evolved into a well-established procedure by becoming the gold-standard therapy for symptomatic MS with favourable characteristics, as reported by the latest 2017 European Society of Cardiology/European Association for Cardio-Thoracic Surgery (ESC/EACTS) guidelines [2]. The European task force highlighted the importance of percutaneous valvuloplasty not only for symptomatic patients (class of recommendation I) but also for asymptomatic ones without unfavourable characteristics and at high risk of thromboembolism or haemodynamic decompensation (class Ila). Mitral valve surgery, despite the proven long-term results [3], remains indicated only for patients with severe MS not suitable for PMC, or as a second-line therapy.

Over the last two decades in Western countries, the prevalence of MS has progressively shifted from rheumatic disease of young patients to degenerative stenosis typical of the elderly, increasing the importance of the non-surgical approach.

Optimal candidate selection for PMC remains the most crucial factor to obtain excellent outcomes [4]. Over the years, many scores which focused on echocardiographic characteristics of the stenotic valve have been proposed to identify predictors for immediate and long-term results [5-7]. The importance of preoperative echocardiographic assessment is recognised by all experienced surgeons and interventional cardiologists; accurate evaluation of not only the dysfunctional valve, but also the subvalvular apparatus and commissural calcifications, impacts the outcomes of both surgical and percutaneous procedures.

The absence of commissural fusion or the presence of severe or bi-commissural calcifications are usually considered major contraindications for PMC, as well as the evidence of left atrial thrombosis, more than mild mitral regurgitation, or concomitant diseases requiring surgery.

Centres which are experienced in mitral valve disease treatment, with a high volume of surgical and percutaneous mitral repair, can achieve good results also in non-optimal candidates, as demonstrated by Dreyfus et al. [8] in a series of 464 patients with unfavourable commissural anatomy. These excellent results, compared to others previously reported for patients unfavourable to PMC [9], can be obtained only with a scrupulous patient selection, an excellent technical performance, and a perfectly integrated cardiac imaging acquisition during the preoperative and the intraoperative phases. The use of three-dimensional echocardiography and computed tomography imaging for preoperative screening plays a fundamental role in optimising patient selection, and allows extremely accurate evaluation of valve pathology [10].

The MVA is frequently used as the first cut-off in MS management due to the strict correlation between MVA and clinical presentation.

In standard practice, a value of MVA lower than $1.5 \mathrm{~cm}^{2}$ is routinely used by operators as a cut-off for PMC indication. Nevertheless, many authors reported good results of valvuloplasty also for moderate or even mild mitral stenosis $\left(\mathrm{MVA}>1.5 \mathrm{~cm}^{2}\right)$ with increased pulmonary pressure or other signs of initial decompensation [11, 12]. In fact, it is common to observe MS-related symptoms even in patients with a MVA greater than $1.5 \mathrm{~cm}^{2}$. Dealing with this class of patients, especially when they are young and have a long life expectancy, is always challenging. In many cases, also

Address for correspondence:

Prof. Francesco Maisano, Department of Cardiovascular Surgery, University Hospital of Zürich, 100, Ramistrasse, 8008 Zürich - CH, Switzerland, e-mail: francesco.maisano@usz.ch

Kardiologia Polska Copyright (C) Polish Cardiac Society 2018

Note: The opinions expressed by the authors are not necessarily those of the journal editors, Polish Cardiac Society or publisher. 
with suboptimal anatomy, PMC could be a good option to delay surgery or at least to diminish symptoms, but only if the decision-making process is held in a high-volume centre with excellent expertise in the mitral valve disease treatment. Young patients with severe MS can benefit from this approach permitting postponement of mitral valve replacement, avoiding a longer anticoagulation regimen in the case of mechanical prosthesis implantation or early deterioration in the case of bioprosthesis.

Tyczyński et al. [13] retrospectively analysed 1794 consecutive patients treated with PMC for symptomatic MS at the Institute of Cardiology in Warsaw since 1988. The results of this study confirmed the efficacy and the safety of the procedure. Moreover, they demonstrated that even the subgroup of patients with preoperative MVA $>1.5 \mathrm{~cm}^{2}$ experienced a significant reduction of the left atrial pressure and an increase of the valve area - two of the most important predictors of good long-term outcomes [14]. As underlined by the authors, going beyond classical indications requires not only demonstration of feasibility but also remarking on the potential periprocedural risks, mainly represented by the possibility of significant post-procedural increase of mitral regurgitation. The failure rate did not significantly differ between the two groups and remained comparable to the values published in literature, permitting new perspectives for PMC indications in the future, if larger randomised studies with longer follow-up confirm these results.

The expansion of PMC indications in the near future should deal with the promising perspectives of new transcatheter mitral valve implantations (TMVI), especially in severe mitral annulus calcification [15]. The available data are still limited and TMVI is often used as a last option for very high-risk patients, bringing 30-day mortality in mitral annulus calcification up to $20 \%$. However, the arrival of new devices in the clinical arena and the increased skill of the operators will probably revolutionise the scenario.

Taking into consideration the worldwide clinical needs, especially in developing countries, the need for a cheap, easily reproducible, percutaneous treatment for MS seems clear. In this scenario, PMC could remain a good option also in the future. The technique is still mainly based on the 30-year-old Inoue balloon, giving a chance for technological improvements in the near future.

However, the management of early or late failure of PMC linked to post-procedural mitral insufficiency or progressive restenosis remains an open issue.

In the next few years, high-volume valve centres should improve their multidisciplinary team organisation, trying to offer a real patient-oriented approach in order to propose the best solution for mitral disease based not only on valve anatomy but also on the patient's characteristics, life expectancy, and future technologies.

Conflict of interest: none declared

\section{References}

1. Inoue $\mathrm{K}$, Owaki $\mathrm{T}$, Nakamura $\mathrm{T}$, et al. Clinical application of transvenous mitral commissurotomy by a new balloon catheter. J Thorac Cardiovasc Surg. 1984; 87(3): 394-402, indexed in Pubmed: 6700245.

2. Baumgartner H, Falk V, Bax JJ, et al. 2017 ESC/EACTS Guidelines for the management of valvular heart disease. The Task Force for the Management of Valvular Heart Disease of the European Society of Cardiology (ESC) and the European Association for Cardio-Thoracic Surgery (EACTS). Eur Heart J. 2017; 38(36): 2739-2791, doi: 10.1093/eurheartj/ehx391, indexed in Pubmed: 28886619 .

3. Reichart DT, Sodian R, Zenker R, et al. Long-term ( $\leq 50$ years) results of patients after mitral valve commissurotomy--a single-center experience. J Thorac Cardiovasc Surg. 2012; 143(4 Suppl): S96-S98, doi: 10.1016/j.jtcvs.2011.09.064, indexed in Pubmed: 22047683 .

4. Maisano F. Expanding the indications for percutaneous mitral commmissurotomy in rheumatic mitral stenosis: look carefully at the commissures, and proceed cautiously and skilfully. Eur Heart J. 2014; 35(24): 1575-1577, doi: 10.1093/eurheartj/ehu103, indexed in Pubmed: 24670712.

5. Iung B, Cormier B, Ducimetière P, et al. Immediate results of percutaneous mitral commissurotomy. A predictive model on a series of 1514 patients. Circulation. 1996; 94(9): 2124-2130, indexed in Pubmed: 8901662.

6. Nunes MC, Tan TC, Elmariah S, et al. The echo score revisited: Impact of incorporating commissural morphology and leaflet displacement to the prediction of outcome for patients undergoing percutaneous mitral valvuloplasty. Circulation. 2014; 129(8): 886-895, doi: 10.1161/CIRCULATIONAHA.113.001252, indexed in Pubmed: 24281331.

7. Wilkins GT, Weyman AE, Abascal VM, et al. Percutaneous balloon dilatation of the mitral valve: an analysis of echocardiographic variables related to outcome and the mechanism of dilatation. Br Heart J. 1988; 60(4): 299-308, indexed in Pubmed: 3190958.

8. Dreyfus J, Cimadevilla C, Nguyen V, et al. Feasibility of percutaneous mitral commissurotomy in patients with commissural mitral valve calcification. Eur Heart J. 2014; 35(24): 1617-1623, doi: 10.1093/eurheartj/eht561, indexed in Pubmed: 24394379.

9. Sutaria N, Northridge DB, Shaw TR. Significance of commissural calcification on outcome of mitral balloon valvotomy. Heart. 2000; 84(4): 398-402, indexed in Pubmed: 10995409.

10. Francis L, Finley A, Hessami W. Use of three-dimensional transesophageal echocardiography to evaluate mitral valve morphology for risk stratification prior to mitral valvuloplasty. Echocardiography. 2017; 34(2): 303-305, doi: 10.1111/echo.13441, indexed in Pubmed: 28240433.

11. Kang DH, Lee $\mathrm{CH}$, Kim DH, et al. Early percutaneous mitral commissurotomy vs. conventional management in asymptomatic moderate mitral stenosis. Eur Heart J. 2012; 33(12): 1511-1517, doi: 10.1093/eurheartj/ehr495, indexed in Pubmed: 22246444.

12. Pan M, Medina A, Suarez de Lezo J, et al. Balloon valvuloplasty for mild mitral stenosis. Cathet Cardiovasc Diagn. 1991; 24(1): 1-5, indexed in Pubmed: 1913784.

13. Tyczyński P, Chmielak Z, Rużyłło W, et al. Percutaneous mitral balloon valvuloplasty: beyond classic indications. Kardiol Pol. 2018; 76(5): 845-851, doi: 10.5603/KP.a2018.0036, indexed in Pubmed: 29589370.

14. Song JK, Song JM, Kang DH, et al. Restenosis and adverse clinical events after successful percutaneous mitral valvuloplasty: immediate post-procedural mitral valve area as an important prognosticator. Eur Heart J. 2009; 30(10): 1254-1262, doi: 10.1093/eurheartj/ehp096, indexed in Pubmed: 19346230.

15. Guerrero M, Dvir D, Himbert D, et al. Transcatheter Mitral Valve Replacement in Native Mitral Valve Disease With Severe Mitral Annular Calcification: Results From the First Multicenter Global Registry. JACC Cardiovasc Interv. 2016; 9(13): 1361-1371, doi: 10.1016/j.jcin.2016.04.022, indexed in Pubmed: 27388824. 